Portland State University

PDXScholar

1975

\title{
Criteria and Outcome of C. S. D. Foster Home and Residential Placements of Court-referred Adolescents
}

Joan Dickey

Portland State University

Follow this and additional works at: https://pdxscholar.library.pdx.edu/open_access_etds

Part of the Social Work Commons

Let us know how access to this document benefits you.

Recommended Citation

Dickey, Joan, "Criteria and Outcome of C. S. D. Foster Home and Residential Placements of Court-referred Adolescents" (1975). Dissertations and Theses. Paper 1920.

https://doi.org/10.15760/etd.1919

This Thesis is brought to you for free and open access. It has been accepted for inclusion in Dissertations and Theses by an authorized administrator of PDXScholar. Please contact us if we can make this document more accessible: pdxscholar@pdx.edu. 
CRITERIA AND OUTCOME OF C.S.D. FOSTER HOME AND RESIDENTIAL PLACEMENTS OF COURT-REFERRED ADOLESCENTS

by

JOAN DICKEY

A report submitted in partial fulfillment of the requirements for the degree of

MASTER OF SOCIAL WORK . 1975

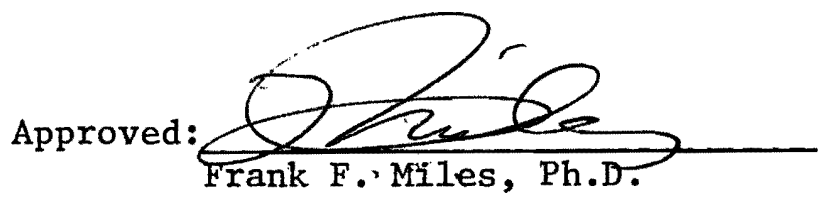


TABLE OF CONTENTS

PAGE

LIST OF TABLES . . . . . . . . . . . . . . . . i ii

CHAPTER

I INTRODUCTION . . . . . . . . . . . . 1

Review of the Literature .......... . 2

Issues on Delinquency

Placements for Adolescents: Institution or Foster Family?

Description of the Referral Process and Agency

Procedure. . . . . . . . . . . . 11

II METHODOLOGY. . . . . . . . . . . . . 13

Purpose. . . . . . . . . . . . . 13

Collection of Data . . . . . . . . . 13

III FINDINGS . . . . . . . . . . . . . 20

Assessment of Characteristics. . . . . . . 21

Involvement with Juvenile Court

Child Characteristics

Family Characteristics

Placement Outcomes . . . . . . . . 31

Summary of Findings. . . . . . . . . . 33

IV CONCLUSIONS. . . . . . . . . . . . . 36

Critique of the Study. . . . . . . . . 36

Implications . . . . . . . . . . . . 38

Recommendations. . . . . . . . . . . 40 
अפVd 


\section{LIST OF TABLES}

TABLE

PAGE

I Age, by Placement and Sex. . . . . . . . . 20

II Number of Court Referrals, by Placement. . . . . . . 21

III Level of Prior Functioning, by Placement . . . . . . 22

IV Underlying Problem, by Placement. . . . . . . . 23

V Number of Court Referrals, by Underlying Problem and Placement................. . . 24

VI Ratings of Academic Factors, by Placement. . . . . . . 25

VII Quality of Peer Relationships, by Placement. . . . . 25

VIII Child Strengths, by Placement. . . . . . . . . 26

IX Child Needs, by Placement. . . . . . . . . . . 27

$\mathrm{X}$ Living Situation, by Placement . . . . . . . . . 28

XI Quality of Relationship with Sibling(s), by Placement. • 29

XII Status after Six-Month Period, by Placement. . . . . . 32

XIII Time Table of Initial Deviation from Plan,

by Placement............... 33 


\section{CHAPTER I}

\section{INTRODUCTION}

This study is concerned with a set of cases referred to Children's Services Division, Marion County, by the Marion County Juvenile Court for placement. Placements include foster homes and residential treatment facilities, including group homes.

The study population of nineteen adolescents includes all those cases placed through Children's Services Division between November, 1973 and April, 1974. These cases are first-time referrals for placement. The entire population includes eight foster home placements and eleven residential treatment placements. The study group may be considered to represent a time cluster sample of a larger population, as it includes all placements during a six-month period.

The objectives of this study are to assess the characteristics of the adolescents and of their families prior to placement and to compare the characteristics of those placed in foster homes with those placed in residential treatment. A final objective is to determine the outcome of placement decisions by finding out where the adolescents are six months after their placement dates in relation to the original placement plans.

The goal of this study is to uncover criteria to determine the appropriateness and the efficaciousness of foster and residential placements for adolescents in order to provide feedback necessary for the development of practice theory. 


\section{REVIEW OF THE LITERATURE}

The selection of the placement facility, closely tied to the anticipated duration and outcome of placement, implies that there is knowledge about the child and his family that is used as a guide in choosing the environment that will most nearly approximate what the child needs for as long as he will need $i t$, and that there are facilities from which a selection can be made. (K1ine and Overstreet, 1972, p. 57)

Much has been written about the lack of specificity on the issue of which child will benefit from what placement. In response to this subject, Kline and Overstreet (1972) have proposed a series of questions as a systematic approach to the decision-making process of child place-

ment. What environmental experiences and qualities are most needed for -

the child's continuing maturation? of these, what can the child accept and adapt to at the time of placement? What qualities or characteristics of the child or in familial relationships preclude the use of a specific resource? What available resource can best provide the child with the experiences he needs and can use?

Most of the literature on placement decisions and planning is addressed to those working with young children; it seems that research on adolescent placement is minimal. However, as the present study focuses on adolescents whose behavior and/or situation have brought them to the attention of the Juvenile Court System, we will present some of the major issues surrounding delinquent behavior in adolescence and some studies and current beliefs concerning out-of-the-home placements for adolescents.

Issues On Delinquency

The adolescents in the present study had been referred by the 
Juvenile Court for placement. Some of them have been labelled as "delinquent" either as a result of their behaviors or of the activities of law-enforcement agencies, including the police department and the Juvenile Court. Although only a minority have committed offenses that would have been considered criminal if committed by an adult, most had been brought to the Court's attention for at least one status offense or conduct: action against community standards or morality that is illegal for children only.

In an article on delinquent-oriented adolescents, Jack Adler (1969) promoted the idea that society fosters delinquency by stressing control over rebellious adolescent behavior. Aggressive and defiant youth pose difficulties because they are hard to manage and disrupt established routines. Adler proposes that families, schools and communities refocus their views on adolescence from control to development by offering opportunities for mastery and for sublimation of energies into constructive channels.

Who is delinquent? In a study of delinquent juveniles in Los Angeles in 1961, Eaton and Polk (Eisner, 1969) showed that delinquency was primarily an adolescent phenomenon that involved boys four times as often as girls. (The U.S. Department of Health, Education, and Welfare's Juvenile Court Statistics, 1970, indicates that although this disparity between sexes is narrowing, boys still are involved with the courts three times as often as girls.) The Eaton and Polk study found that children from broken homes had an increased risk of delinquency. A study of fifteen year olds, in 1963, by Hathaway and Monachesi (Eisner, 1969), supports the finding of higher delinquency rates for 
children from broken homes. They found that delinquency rates varied inversely with socioeconomic status and with high-school rank but did not vary with intelligence levels. By following the subjects for four years, they found that delinquency rates decreased as their population reached nineteen years of age.

Sociologists (Martin, 1959) have suggested that studies on juvenile offenders have avoided, in the past, but should stress in the future, the particular kinds of delinquency. The assumption that the types of offenses committed by children are of little or no consequence in either individual case appraisals or in social research has led to inadequate treatment planning and misleading research finding.

One attempt to categorize types of delinquency was a research survey on juvenile court records of 845 youth by Kratcoski (1974), in which groups were compared by dividing the illicit acts into "delinquent," those considered criminal if committed by adults, and "unruly," those that are considered offenses because of the juvenile's age. $72 \%$ of the boys and $48 \%$ of the girls had committed "delinquent" acts, whereas $28 \%$ of the boys and $52 \%$ of the girls had engaged in "unruly" acts. In addition, Kratcoski found that $45 \%$ of the boys and $59 \%$ of the girls were from homes from which at least one parent was absent. These findings led him to speculate that boys more often escape the effects of an unhealthy family situation by finding companionship and support from peer groups whereas girls tend to escape by running away (an "unruly" act).

Included among the many divergent theories on the effects of an incomplete or inefficient family structure on delinquency are Bowlby's 
contention that maternal deprivation leads to the "affectionless characters" seen in some delinquents, Glueck and Glueck's theory that boys from homes without fathers have increased risks of delinquency and Bordua's idea that without a role model at home, adolescent boys have difficulty in forming a proper masculine self-image and act out to prove their masculinity to themselves and to their peers (Eisner, 1969). The lack of a wholesome family experience is only one of several factors to which social scientists have attributed delinquency. Other variables promoted as being involved in delinquency causation are childrelated characteristics, such as physical inadequacies, mental deficiencies, personality maladjustments; peer group and/or gang pressures; quality, size and racial composition of neighborhood; and school expectations and conditions.

Without explicitly focusing on adolescents, Korner (1963) has attempted to differentiate children who act out by comparing sociological delinquents and individual delinquents. The sociological delinquent displays behavior against authority which is forbidden by society. He holds his environment responsible for his acting-out. The individual delinquent behaves toward people as if he were repeating certain earlier experiences with his parents. Generally, he is emotionally disturbed and needs environmental support in order to work through his problems. Korner suggests that the sociological delinquent needs a placement based on environmental change, such as a camp. The individual delinquent who displays mild acting-out can benefit from a foster family; the child who displays severe acting-out requires institutional placement.

In an article reviewing the literature on theoretical formulations 
and research studies of middle-class delinquency, Shanley (Reed and Baali, 1972) summarized the complexity of subject matter in terms of etiological dimensions. Among the eight that he cited are anxiety regarding sex role identification, weakening of the deferred gratification principle, inadequate parent-child relationships, ineffective school performance, influence of deviant peer groups, and experimentation with deviant behavior practices. The results of his literature survey suggested the need for further studies to obtain basic descriptive data on delinquent behavior among middle-class adolescents. of particular relevance to the present study are his proposals to investigate the association between negative school experience and delinquency and of the relationship between different patterns of childrearing practice and delinquent behavior.

\section{Placement For Adolescents: Institution or Foster Family?}

The concept and development of substitute care appears to be based on assumptions, norms and societal values rather than on empirical evidence. The following principles continue to permeate the literature: all efforts must be made to maintain and restore the parent-child relationship; another family is the best place for a child if his own family cannot care for him; and, if a child cannot return home, the goal is to provide him the security and feeling of belonging within a foster home. In the past the concerns of practitioners seem to have centered on an idealized view of the institution of the family; current practitioners are re-focusing on the needs, rights and best interests of the child (Meisils and Loeb, 1956).

Draza Kline, a pioneer in differential placements for children, 
believes that when pathology in the family situation is predominantly destructive to the child and cannot be adequately modified by treatment methods geared to the preservation of the family, an out-of-the-home placement should be considered. The appropriateness of placement plans must be evaluated in terms of the diagnosed needs of the child and of the family (Matek, 1964).

The issue of group versus family care has been debated for many years by clinicians (Wolins and Piliavin, 1964). At present, the consensus among substitute care workers appears to indicate that institutional settings are most appropriate for disturbed children, children who are uncomfortable in close relationships, children whose parents vehemently oppose foster family care and adolescents (Maas and Engler, 1959). All other children, especially those under six years of age, are regarded as most properly cared for in foster homes.

Among the important factors for placement decisions and planning is the knowledge of how long any child will remain in placement. Jenkins' study (1967) indicates that one-half of the children who entered foster care in 1963 were discharged within three months. Fanshel's study (1971), which excluded children who were in substitute care for less than ninety days, found that three out of ten children leave placement within the first year after entry. These findings confirm those of Maas and Engler (1959), who studied a national cross section of children in placement and found that the major exodus from substitute care occurs during the first year of placement. A study of longitudinal records of 410 boys between the ages of eight and fífteen who were in placements (Ambinder, 1965) suggests some 
differences in the length and number of placements among different age groups. Each record was examined to determine the number of placements, of at least a three month duration, since birth, for each boy. The study population was characterized by a large amount of movement, with the older children having more placements than the younger ones. An unexpected finding of the study was that if a boy had not acquired foster child experience early in life, he tended to have had a more difficult time finding a stable living arrangement in pre-adolescent and adolescent years.

Transfer of a child from one placement to another may be initiated by an agency for good cause, by foster parents because they can no longer tolerate a child's behavior, or by insistent, unstable parents. Ambinder (1965) found that the probability of circumstances requiring re-placement is far greater with older children. A study in Oregon (Hunter, 1964), arising out of concern over high-turnover rates of foster homes for teenagers, found that of 95 families recruited as foster homes for teens in a one year period, only 35 were still caring for or were available to adolescents two years later; and, of these, 16 families said they would not be interested in caring for any other adolescents.

It is common practice among child welfare workers not to ask adolescents to form new ties to new parental figures and not to ask foster parents to form new ties with adolescents. It is believed that foster family care is not for the adolescent who is trying to emancipate himself and who has unresolved concerns about how his own family feels towards him (Foy, 1967; Fredericksen and Mulligan, 1972). The insecu- 
rity involved in moving in with strangers and the constant fear of removal may influence the adolescent to prove that the foster home is intolerable, even if it appears to be the treatment of choice (Littner, 1960).

Group homes, now considered the placement of choice for adolescents, (Stone, 1969) are residential programs that generally lie in the areas between a completely institutional life and a completely free 1ife. For the adolescent whose parents foster delinquent behavior or are unable to provide the guidance necessary for successful adjustment, the group living situation involving a limited number of peers represents a residence offering space, structure and constructive concern (Carpenter, 1963).

Kline and Overstreet (1972), while advocating group facility placements for adolescents, contend that due to inadequate ego defenses and poor impulse control the adolescent will benefit from a structured environment with built-in supports. The group home provides opportunities, but not expectations for close relationships with adults. It allows the adolescent to invest his energy into peer relationships.

In order to benefit from a group home placement, an adolescent needs a high "developmental potential" (Gil, 1964). He must be of average intelligence and possess sufficient strength to develop adequate behavior controls to manage independently of the house and the staff (Carpenter, 1963). He must have the capacity for forming relationships. He must accept and perform adequately. in public school (Glassock, 1959). Burnes and Raczkowski (1972) have proposed a synergistic model for group home care of juvenile offenders that seeks to promote life 
adjustment and individual growth. They contend that a recidivism rate of $85-95 \%$ for offenders released from custodial, institutional facilities and training schools, compared with a much lower rate for probationers discharged from short-term detention, indicates that more institutionalization leads to higher risks of subsequent delinquency. The major components of their model, including prognostic versus diagnostic admissions decisions, prescriptive and prevocational learning situations, completely scheduled daily time, parent counseling and weekends at home, and specific discharge contingencies, lead to early program acceptance, reduced length of stay, minimal recidivism and major family pattern alterations. They believe that their model succeeds where others have failed, not merely because of the sufficiency of personnel, skill levels and funds, but because of adequate planning, implementation and follow-up combined with regard for inseparable and indispensable practices.

Among these inseparable and indispensable practices is the need to evaluate placement decisions and placement outcomes. Through a national survey of child placement agencies, Stone (1969) found that $73 \%$ of the responding agencies were not conducting any studies of children in placement currently under their supervision and that $87 \%$ of the agencies were not doing any post-discharge or follow-up studies to placement. Her concern over the large gap in knowledge of what is being accomplished by the existing foster care system is the springboard for this present study that aims at evaluating the method and the efficaciousness of current practice with adolescents. 
II. DESCRIPTION OF THE REFERRAL PROCESS AND AGENCY PROCEDURE

Between November 1, 1973 and Apri1 30, 1974, Marion County Juvenile Court referred 34 cases for placement to Marion County Children's Services Division. Of these, 19 adolescents were placed in either foster homes or in residential treatment units, including group homes. A11 19 cases were first-time official placements made by C.S.D. The remainder of referrals were withdrawn, placed informally with relatives or dropped.

All referrals made to C.S.D. by the juvenile court are handled by one particular worker. She has ultimate responsibility for these placement decisions. Juvenile Court counselors are requested to provide an extensive study of the child and of his family to C.S.D. at the time of referral. This narrative includes identifying information, description of problem, school performance and attitude, family relationships, parents' and child's attitudes about placement, legal status and placement recommendations. (Appendix)

With this information and through subsequent contacts with the Juvenile Court counselor and with the child and his family, the C.S.D. worker determines the appropriateness of residential treatment or foster care. She chooses from available resources the available facility or home that can most adequately provide the child's diagnosed needs. Following placement, she writes reports on each child stating the reasons for placement, the variables considered in determining the appropriate placement, the child's initial reaction to placement and recommendations for the ongoing workers regarding the case. These 
records are written in a consistent style and provide an outsider with information on the critical factors involved in making placement decisions and in formulating placement plans.

With several of these 19 cases, the Juvenile Court counselor, prior to referral to C.S.D., had formulated and initiated placement plans. If deemed appropriate by the C.S.D. worker, her task subsequently consisted of formalizing the decision through proper channels and arranging for payment to the placement facility. When she had serious doubts concerning the feasibility of the recommendation, the case plan was presented to a Review Committee for additional input regarding placement.

All of these 19 cases were transferred to other workers in ongoing services units at C.S.D. once the placement was considered to be "secure." In most instances, this meant a time period of two to three weeks after the actual placement date. 


\title{
CHAPTER II
}

\author{
METHODOLOGY
}

\section{PURPOSE}

The present study is descriptive and exploratory. One objective is to assess the population, adolescents in placement, and to compare two subgroups on this population, those in foster home placements and those in residential treatment placements. I hope to uncover measurable differences between these two groups. A second objective is to begin to assess placement decision-making by determining the child's situation six months following the placement date and comparing it with the original placement plan.

\section{COLLECTION OF DATA}

Prior to finalizing a research design, I examined four case records, chosen at random out of the study population, to determine the amount of available information. The letters of referral from the Juvenile Court counselors included sufficient data on the child and his family to extract several possibly important variables. The Children's Services Division narrative, written at the time of placement, suggested those characteristics of the child and of his family that influenced the particular placement decision. Some of the cases provided additional information through records of previous family involvement with C.S.D. or reports submitted by doctors, social workers or psychologists 
from other agencies. Ongoing C.S.D. workers furnished periodic records stating the child's current location and situation.

My impression was that there was sufficient written data to base the research around close examination and extraction of variables from the case records. The collection of data occurred in 1ate Fa11, 1974, which allowed at least a six-month period of time following placement in all cases. I wanted to determine where the child was in relation to the original placement plan six months after placement; this could be obtained either through the written records or by brief informal interviews with the workers assigned to ongoing cases.

All case records were then examined by the same researcher. Factual information on the child and on his family was recorded on a checklist designed to allow the examiner to note the presence or absence of specific traits, behaviors, school performances, juvenile court involvements, peer and sibling relationships, strengths and needs. The same checklist was used to extract family and parental characteristics, including marital status and relationship, parent-child relationships, family values and expectations and attitudes toward placement.

The following list consists of all the variables that were recorded and shows how the checklist was organized.

\section{Child Characteristics}

Age at Placement Date

Sex

Juvenile Court Involvement: Court Wardship, Number of Court Referrals

Delinquent Behaviors: Promiscuity, Truancy, Runaway, Drug Involvement, Beyond. Parental Control, Curfew, Burglary Previous Substitute Care Arrangements: Friends, Relatives, Shelter Care, Detention

Previous Institutional Care

Previous Foster Home Placement 
School Life: Long-standing History of School Problems, Intelligence, Achievement, Adfustment

Peer Relationships: Quality, Exclusively Delinquent Friends

Placement Decision Factors

Behavioral Traits: Difficulty Relating to Authority, Manipulative, Stubborn, Withdrawn, Depressed, Hostile, Suspect Emotional Disturbance

Child Strengths: Likeable, Attractive, Contributing to Environment, Academic Strengths, Social Skills

Child Needs in Placement: Family Atmosphere, Strong Guidelines, Well-supervised Activities, Adult Understanding, Warmth, Independence

Family Characteristics

Absence/Presence of Mother and Father

Relationship: Natural, Adoptive, Step-parents

Parents and Step-parents Outside the Home

Number of Divorces

Physical Illnesses or Confinements

Serious Mental or Emotional Problems

Child and Step-parent Conflict

Siblings:

Number and Ages of Brothers, Sisters, Step-brothers, Stepsisters

Absence/Presence of Siblings In the Home

Child Relationship with Siblings

Siblings Placed in Residential or Foster Care

Siblings' Involvements with Juvenile Court

Parental Traits:

Marital Relationship: Frequent Fighting, Fear of Spouse, Conflict over Child-rearing Techniques

Parent-Child Relationship: Erratic Handling, Authoritarian Approach, Extreme Permissiveness, Lack of Attention and/or Demonstration of Concern, Suspiciousness, Rigid Outlook, Favoritism, Recognition of Individual Differences Between Children, Promoting Child Dependency, Importance of Religion in Family, High Expectations (Social, Academic, Moral)

\section{Court Referral. Process}

Request for Placement in Foster or Residential Care

Request for Specific Placement Facility

Worker's Judgment of Case: Family Problem, Child's Emotional Problem, Child's Delinquent Behavior; Workable Case

As expected, there were some inherent problems resulting from the use of an absence/presence checklist. When a characteristic was implied, 
it was recorded as being present. An example of an inferred need for "structure" is the statement that "she needs a place she can find some independence without engaging in destructive behavior." The statement, "he will respond to a supportive therapeutic environment," suggests that the case is "Workable." When a characteristic was neither mentioned nor implied, it was checked off as being absent.

To circumvent the difficulties encountered with this all-or-none principle, some variables were recorded on a positive-negative continuum $(-2,-1,0,+1,+2)$. Factors involved in "School Life" were assigned values such that intelligence, achievement and adjustment ratings represent a comparison to the average adolescent student.

In similar fashion, the quality of peer relationships and sibling relationships was noted on rating scales. When neither strengths nor weaknesses in these areas were mentioned, they were given a rating of 0 . Positive and negative values were assigned in relation to the intensity or severity and to the significance placed upon the area by the report writers.

Two identical checklists were used in collecting the data, one for recording information on children placed in foster homes and the other for children placed in residential treatment. It would have been preferable to record without differentiating these two groups and possibly introducing bias; however, due to the conditions of having only one examiner and basing the data collection solely on case records, it was impossible to record variables without awareness of the placement decision.

At this point, a definition of terms is necessary. In the present 
study, placement is defined as a situation arranged and supervised by C.S.D. In which care of the child outside of his own home is provided on a 24-hour basis by specified care-taking people or agencies. None of these 19 placements was originally planned to be temporary or shortterm; all were decided upon the basis that the child was in need of placement for at least six months. Foster home (F.H.) is defined as that situation in which a single person, a married couple or a family care for an unrelated child in their home on a 24-hour basis. The term, residential treatment (R.T.), is employed to cover those situations in which institutions or group homes assume around-the-clock care of children whom they have accepted into their programs. The use of the term, residential treatment, was chosen to cover a variety of programs, group facilities and institutions and was not meant to imply that treatment either does or does not occur in these placements. It should be mentioned that although most of the adolescents in this study have engaged in delinquent acts, none of them were placed in institutions that are known as state training schools for the delinquent.

Each case record was exămined separately on a one-time only basis, except for the four records perused prior to finalizing the checklist. Absence, presence or value for each variable was assigned after thoroughly reading a record and while the written material was still available for consultation. Admittedly, the information collected is not without bias and reflects both the perspectives of the workers who originally recorded the data and the interpretations of the present researcher, who is solely responsible for the evaluation and recording of variables and for some unavoidable subjective judgments necessary for 
the complete compilation of data.

The order in which records were chosen for study was determined exclusively by an uninvolved C.S.D. secretary who located and pulled a specified number of files at the researcher's request. In all likelihood, she initially gathered those records which were easiest to locate, but the circumstances involved in the ease with which records can be pulled for study are beyond the scope of the present paper.

One of the original objectives of this study was to uncover which placement decisions and plans were successful and which were unsuccessful in order to correlate outcome with child and family characteristics. Several difficulties became apparent as attempts were made to operationally define the concepts of "success" and "failure." Would a successful placement plan be signified by the child remaining in the original placement for at least six months, regardless of his adjustment to or functioning within that home or facility? Would a placement plan be considered unsuccessful if a child were moved to another placement during the six-month period due to closure of the original placement facility? Would a child's transfer from one foster home to another home that could more adequately meet his changing needs connote success or failure?

It is obvious that under the circumstances of this study, the outcome of placement decisions is inextricably bound with the implementation and follow-through of planning and treatment. As attempts were not made to gather data on and/or to evaluate the ongoing C.S.D. worker's participation with the child in placement, the effectiveness of the particular treatment offered by the placement facility or the 
specific functioning of the child during or after placement, there were too many unrecorded variables to devise even tentative concepts of successful placements.

As an alternative, the objective was changed to deciphering the location of these adolescents six months after their actual placement dates and to record any major deviations from the original placement plans. By comparing drop-out rates from foster homes with rates from residential treatment facilities, we might gain some insight into which resources are more appropriate for adolescents.

In a similar manner, by comparing characteristics of those children who were placed in foster homes with those placed in residential treatment, we hope to uncover definitive diagnostic and prognostic material that differentiates these two groups. Although a variety of cross-tabulations of traits and characteristics are possible, the present study, due to time, manpower and financial limitations, primarily relies on groupings by placement to compare variables. 


\section{CHAPTER III}

\section{FINDINGS}

The total number of cases studied was nineteen. Eight were placed in foster care and eleven were placed in residential treatment centers, including group homes. In foster homes (F.H.), there were six girls and two boys. In residential treatment (R.T.), there were three girls and eight boys. Table I represents a breakdown according to placement, age at placement and sex.

\section{TABLE I}

$$
\text { AGE, BY PLACEMENT AND SEX }
$$

13

$$
\begin{aligned}
& \text { Age } \\
& 1415 \quad 16 \\
& 17
\end{aligned}
$$

$$
\text { F.H. }
$$

Boys

$4 \quad \begin{aligned} & 1 \\ & 2\end{aligned}$

$$
\text { R.T. }
$$

Girls

Boys

$\begin{array}{lll}1 & 2 \\ 1 & 1 & 5\end{array}$

These figures indicate that girls are more 1ikely to be placed in foster homes and boys in residential treatment. Regarding age, these figures are consistent with Hathaway and Monachesi's findings (Eisner, 1969) that delinquency rates for a population of fifteen year olds decreased as the same population reached nineteen years of age. 


\section{ASSESSMENT OF CHARACTERISTICS}

\section{Involvement With Juvenile Court}

A11 of the adolescents were made "Wards of the Court" at the time of placement, if not prior to that time. This wardship by the court is not a significant variable in that all cases referred through the Court to C.S.D. for placement planning, arrangement and supervision necessitate court action.

The majority of these adolescents, prior to the decision to place, had been involved with the Juvenile Court System. Table II represents the number of court referrals for each child up to the time of placement. TABLE II

NUMBER OF COURT REFERRALS, BY PLACEMENT

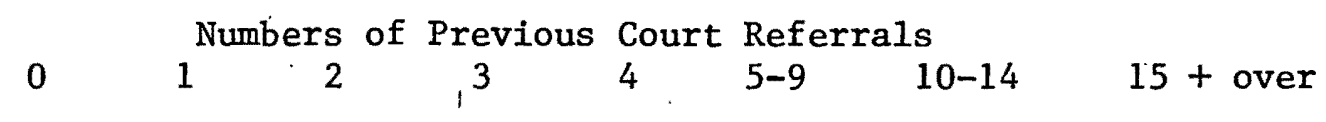

$\begin{array}{llllllll}\text { F.H. } & 2 & 2 & 1 & & 2 & 1 & \\ \text { R.T. } & \cdot & 2 & 2 & 1 & 4 & 1\end{array}$

These figures indicate that those placed in residential treatment tend to have had a more extensive history of contact with the courts. The F.H. median is about 2.5, while the R.T. median is about 5.0 , or twice as high.

There was 1ittle difference in the types of delinquent behaviors engaged in by those placed in foster care versus those placed in residential treatment care. There seemed to be equivalent numbers of truancy, runaway, drug abuse and "beyond parental control" within the two groups. The only category in the delinquent behaviors that showed a wide discrepancy was "burglary"; one of the foster care (12.5\%) versus 
eight of the residential treatment group (72.7\%) had been involved in such behavior.

Prior to placement by C.S.D., all cases, at some time, had been in "substitute care." Substitute care includes shelter homes, foster homes, institutional placements, detention and informal placements with friends or relatives. The numbers and types of earlier placements did. not differ significantly between the foster and residential groups.

The referral counselor included a description and judgment of the child's functioning in the most recent substitute care arrangement, which generally was a temporary stay in detention or shelter care while awaiting a placement decision and plan by C.S.D. Table III shows how the cases were arranged on the rating scale. (A value of 0 was assigned when mention was not made of the behavior and/or attitude.)

\section{TABLE III}

LEVEL OF PRIOR FUNCTIONING, BY PLACEMENT

$$
\begin{array}{lccc}
\text { Rating for Functioning } & & \\
-2 & -1 & 0 & +1
\end{array}
$$

$\begin{array}{llllll}\text { F.H. } & & & 2 & 1 & 5 \\ \text { R.T. } & 1 & 4 & 3 & 2 & 1\end{array}$

Functioning in substitute care, immediately prior to placement, was viewed by court counselors as at a higher level among those who were subsequently placed in foster homes. It may be that those with adaptability and coping skills are more likely to be placed in foster homes. Or, it may be that substitute care provides a new environment that is devoid of the former pressures of family, peers and school. In any case, acceptable substitute care performance may have influenced the decision to place in foster homes. 
Included in the court letter of referral for placement was the court worker's judgment, implied or stated, on the major underlying problem area related to the child's behavior. In a few cases an extensive history of emotional difficulties was considered to be at the base of the child's acting-out. In other cases, the current difficulties of the adolescent were thought to be significantly influenced by dysfunctional families or were seen to be reflective of severe stresses within the family. The third category represents those cases in which the worker believed the child's behavior to be accurately labelled "delinquent." This category includes those adolescents whose behavior could not be adequately explained on the basis of familial relationships or of identifiable personality conflict.

\begin{tabular}{lccc}
\multicolumn{5}{c}{ TABLE IV } \\
\multicolumn{5}{c}{ UNDERLYING PROBLEM, BY PLACEMENT } \\
\multicolumn{4}{c}{ Problem Area } \\
& \multicolumn{4}{c}{ Emotional Problem } & Family & Problem & Delinquency \\
F.H: & 1 & 6 & 1 \\
R.T. & 1 & 4 & 6
\end{tabular}

These findings indicate that the behavior of those eventually placed in foster homes more often reflects the adolescent's reactions to familial stress and strain. It may be that these adolescents have failed to secure from the family the satisfactions and recognition necessary for adjustment to community standards. It may be that potentially "illegal" situations offer these youth an escape from the hurt of lack of love and attention experienced within the family.

By comparing the number of court referrals for groups separated by the underlying problem areas, Table $\mathrm{V}$ presents findings that indicate 
the discrepancy in the amount of acting-out behavior, as noted by the Court.

TABLE V

NUMBER OF COURT REFERRALS, BY UNDERLYING PROBLEM AND PLACEMENT

\begin{tabular}{|c|c|c|c|c|c|c|}
\hline \multirow[b]{3}{*}{ F.H. } & \multicolumn{4}{|c|}{ Underlying Problem } & \multirow{2}{*}{\multicolumn{2}{|c|}{ Delinquency }} \\
\hline & Emotic & 1 Problem & Family & Problem & & \\
\hline & $(N=1)$ & 0 & $(N=4)$ & 17 & $(\mathrm{~N}=1)$ & 7 \\
\hline R.T. & $(N=1)$ & 2 & $(\mathrm{~N}=6)$ & 24 & $(N=6)$ & 51 \\
\hline Total & $(\mathrm{N}=2)$ & 2 & $(\mathrm{~N}=10)$ & 41 & $(\mathrm{~N}=7)$ & 58 \\
\hline
\end{tabular}

Those adolescents whose delinquent behavior could not be explained by intrapsychic difficulties nor by problematic family situations came in contact with the Court system more often than the other two groups. As these judgments (emotional, family or delinquency problem) were made by the court worker at the time of referral for placement, it may simply be that the number of court referrals influenced the worker's decisionmaking of naming or implying the major underlying problem area. Or these findings may tentatively confirm Korner's classification scheme (1963) of differentiating those children who act-out against authority and hold the environment responsible for their behaviors from those children who act-out in attempts to work through problems experienced earlier in their homes. We would speculate that adolescents who neither acknowledge nor are aware of being responsible for their own behaviors might engage in delinquent acts more frequently than would adolescents who were in touch with the pains and voids in their home lives.

\section{Child Characteristics}

School Life. More than one half of the adolescents in both foster 
homes and residential treatment were reported to have had histories of school problems. However, when this was broken down into different components, a slightly different picture emerges.

TABLE VI

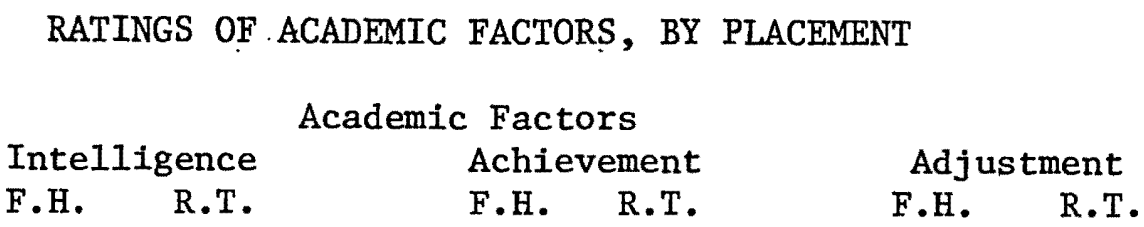

$\begin{array}{rrrrrrr}+2 & & & 1 & & 2 & \\ +1 & 5 & 4 & 1 & & 1 & \\ 0 & 1 & 4 & 4 & 1 & 2 & 2 \\ -1 & 2 & 3 & 1 & 5 & 2 & 7 \\ -2 & & & 1 & 5 & 1 & 2\end{array}$

Judgments about intelligence levels do not seem to vary between the groups and indicate that most of the adolescents are within the average range. In both school achievement and adjustment, those placed in residential treatment are rated lower than the foster home group.

Peer Relationships. The quality of these adolescents' friendships is difficult to judge but most of the records included some evaluation of the child's relationships with peers. Two of the foster group and five of the residential group were reported to have exclusively associated with other "delinquents." Table VII represents the ratings assigned on peer relationships for each child.

TABLE VII

QUALITY OF PEER RELATIONSHIPS, BY PLACEMENT

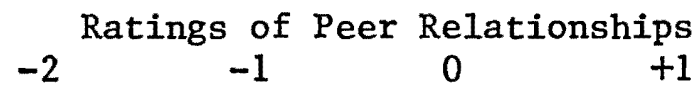

$\begin{array}{llllll}\text { F.H. } & 1 & & 3 & 2 & 2 \\ \text { R.T. } & 1 & 9 & 1 & & \end{array}$

Those placed in foster homes were seen as having better relation- 
ships with peers. It is interesting to note that none of the R.T. group was reported to have had positive relationships with peers. Mention was made in the records of three boys in the R.T. group that these adolescents associated solely with children of much younger ages. We would speculate that competence anxiety and insecurity interfered . with the establishment of healthy peer relationships.

Placement Decision Factors. A checklist for "typical" adolescent problems was used to compare the numbers and types of difficulties experienced by the Foster group with those of the Residential group. This list included problems with authority, manipulative behaviors, stubbornness, withdrawal, depression, hostility and emotional disturbances. The incidence in both groups for all of these problems was equivalent.

Another list for child strengths that were mentioned in the records does indicate dissimilarities between the groups.

TABLE VIII

CHILD STRENGTHS, BY PLACEMENT

\begin{tabular}{ccccc} 
Likeable & \multicolumn{2}{c}{ Child Strengths } & & \\
4 & Attractive & Giving & Academic & Social \\
2 & 4 & 4 & 3 & 2 \\
2 & 4 & 1 & 0 & 0
\end{tabular}

Those placed in foster homes seem to have more strengths that are noticed by workers. It may be that those placed in residential care have strengths that are less obvious to others or that their talents lie in other areas that are not seen prior to placement.

Both the referral letter and placement report contained those needs of the child that were considered during the decision-making process. Half of the adolescents in both groups were in need of adult 
understanding and warmth. Table IX shows the degrees of different needs in the two groups.

TABLE IX

CHILD NEEDS, BY PLACEMENT

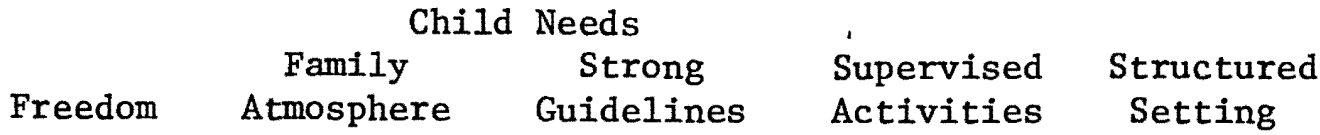

$\begin{array}{rrrrrr}\text { F.H. } & 5 & 4 & 3 & 1 & 2 \\ \text { R.T. } & 3 & 1 & 9 & 6 & 10\end{array}$

These findings indicate that those for whom residential treatment is chosen are considered to be in need of limit-setting, guidance and supervision. These child needs coincide with what most group homes and institutions offer to adolescents in their placements.

\section{Family Characteristics}

Less than half of the adolescents prior to placement continued to live with an intact family of origin. Five of the F.H. group and five of the R.T. group had experienced at least one divorce within their families. Many had been indirectly involved with more than one divorce; the numbers are not clearly discernible due to the mobility of some parents and step-parents, the frequency with which partners were changed and inadequate data on marital statuses and changes in the records.

Table $\mathrm{X}$ shows the living situation for each adolescent prior to . placement. Many of the adolescents frequently moved between the homes of mothers and fathers in cases of divorce and subsequent separate households. These figures represent the most recent family environment for the child immediately prior to shelter care, detention or placement. 
TABLE X

LIVING SITUATION, BY PLACEMENT

Prior Living Situation

Mother \& Father Mother only Father only Step-parent in home $\begin{array}{lllll}\text { F.H. } & 3 & 2 & 1 & 2\end{array}$

$\begin{array}{lllll}\text { R.T. } & 5 & 2 & 1 & 3\end{array}$

Four adolescents within this study had been adopted. One girl in the F.H. group had been adopted by her natural mother's husband and eventually was left by the mother to live with her adopted father. Three of the residential group had been adopted, two of whom had been adopted in infancy, had lost their adoptive mothers through death and lived with their adoptive fathers and step-mothers at the time of placement. The third in the R.T. group had been adopted by his natural mother's husband prior to the mother's divorce from this man and her marriage to another person.

Siblings. Information was collected on the number and ages of siblings and step-siblings within the family. There were no "only children." in this study. Family sizes ranged from two children to six children. There were no significant findings relating to the ranking of the adolescent according to birth order.

Values were assigned to the child's relationship with his or her siblings. Negative values were assigned when the relationships were marked by constant conflict, destructiveness or unhealthy competitiveness. Positive values were given to relationships that were strengthening, generally harmonious, constructive and nurturing. 
TABLE XI

QUALITY OF RELATIONSHIP WITH SIBLING(S), BY PLACEMENT

Rating of Relationship with Sibling(s)

$\begin{array}{lllll}-2 & -1 & 0 & +1 & +2\end{array}$

$\begin{array}{llllll}\text { F.H. } & 1 & 3 & 2 & 1 & 1 \\ \text { R.T. } & 4 & 1 & 3 & - & 3\end{array}$

We speculate that some of the adolescents' negative feelings toward siblings might have been influenced by favoritism displayed by parents towards a particular child. Four of the five in the R.T. group with negative relationships with siblings came from families in which parental favoritism was present.

Three of the F.H. group had siblings who were placed outside of their homes either through the Juvenile Court or through C.S.D. One additional case in the F.H. group had an older sister who had had extensive involvement with the Juvenile Court System." No one in the R.T. group was reported to have had siblings officially placed outside the home. One child in the R.T. group had siblings who were heavily involved with drugs and who were well known to the Juvenile Court.

Parents. Several studies (Hutchins et a1., 1972) have found that placement is frequently necessitated by the physical or mental illnesses of the parents. Sauber (1967) found that in $29 \%$ of the families she studied, placement was related to physical illness or confinement of the main child-caring person and in an additional $11 \%$ of the families, child placement was related to the mental illness of the mother. The present study neither expected to uncover nor did find such a high percentage of parental health disabilities associated with the preplacement situations of families. Two mothers were reported to be afflicted with physical 
11lnesses or diseases and one mother had severe long-standing emotional problems; three fathers had physical disabilities. We would surmise that the health status of parents of a select group of adolescents would be much less influential in placement decisions than would be the health of parents of a large sample of children of all ages in placement.

Checklists were made on characteristics of marital and parentchild relationships that might influence the child's behavior. Marital relationship variables included severity of parental fights, fear of the marital partner, and conflict over child-rearing methods. Parent-child relationship variables included authoritarianism, extreme permissiveness, lack of attention and/or demonstration of love, rigid outlook, unreasonable expectations, suspiciousness and favoritism towards another child.

There was very little difference between the numbers of these characteristics that were present in the F.H. and R.T. groups. This does not necessarily mean that there were not differences between the families of the two groups. The checklist did not allow for the recording of the importance of a particular "negative" trait to the adolescent's functioning within that environment. An example of this is a girl from the F.H. group whose parents were extremely authoritarian. She had been functioning adequately until adolescence at which time the parents' attempts to stifle her efforts towards independence caused conflict in the child and the family.

Due to the frequency with which some marital partners were in and out of the home, the accuracy of some of the recorded information on marital relationships is questionable. It was difficult to ascertain whether conflict between parents or fear of the other parent referred 
to a present marital spouse or to an ex-spouse who was physically removed from the family.

\section{PLACEMENT OUTCOMES}

One of the goals of this study was to determine where the child was six months after the placement date in relationship to the original placement plan. All but one of the case records contained adequate information to ascertain the movements between different placements, home and "on the run" status made by the adolescent during this sixmonth post-placement period. Verbal contact was made with the ongoing C.S.D. worker assigned to the one case whose written records were insufficient for present purposes.

At the end of six months, two of the original eight placed in foster homes remained in the same settings and five of the original eleven placed in residential treatment remained in the same setting. One of the F.H. group reached the age of eighteen and was therefore "graduated" and one of the R.T. group successfully completed the specific course offered by the particular residential unit and was "graduated."

After six months, the remaining ten adolescents were in settings other than those which had been planned for them at placement. Four of the F.H. group had been moved through official C.S.D. changes arising from conflict between the adolescent and the foster parents, "closure" of a foster home or mutual agreement among all involved parties that a change was warranted. Two of the R.T. group had been dismissed by the residential setting due to extreme behavioral problems and had been 
returned home. One of the F.H. group and three of the R.T. group had run from their placements during the six-month period.

TABLE XII

$$
\text { STATUS AFTER SIX-MONTH PERIOD, BY PLACEMENT }
$$

Remains Graduated $\begin{gathered}\text { Status } \\ \text { Official Change Run Dismissed }\end{gathered}$

$\begin{array}{llllll}\text { F.H. } & 2 & 1 & 4 & 1 & 0 \\ \text { R.T. } & 5 & 1 & 0 & 3 & 2\end{array}$

The seven who remained in placement and the two who "graduated" from placement can be considered cases which followed the original placement plans. The four who ran away and the two who were dismissed from placements are cases which greatly deviated from the plan and which may reflect inappropriate placement decisions. The four who were changed in placements through C.S.D. channels may be cases that reflect inadequate planning and implementation of the original placement decisions. Whatever the reasons for deviation from the original decisions, it is disturbing to see that only nine of nineteen placement plans were either still in effect or had been completed after a period of six months. The higher attrition rate for the F.H. group is consistent with Hunter's study (1964) on the high turn-over rates of foster homes for teenagers.

- Inasmuch as several adolescents had changed placements more than once during the six-month period, Table XIII was designed to represent a breakdown of "first deviations" from the original placement plans, according to the post-placement month. 
TABLE XIII

TIME TABLE OF INITIAL DEVIATION FROM PLAN, BY PLACEMENT

Months Following Placement
1st $\quad \begin{array}{llll}\text { 2nd } & \text { 3rd } & \text { th } & \text { th }\end{array}$ 6th

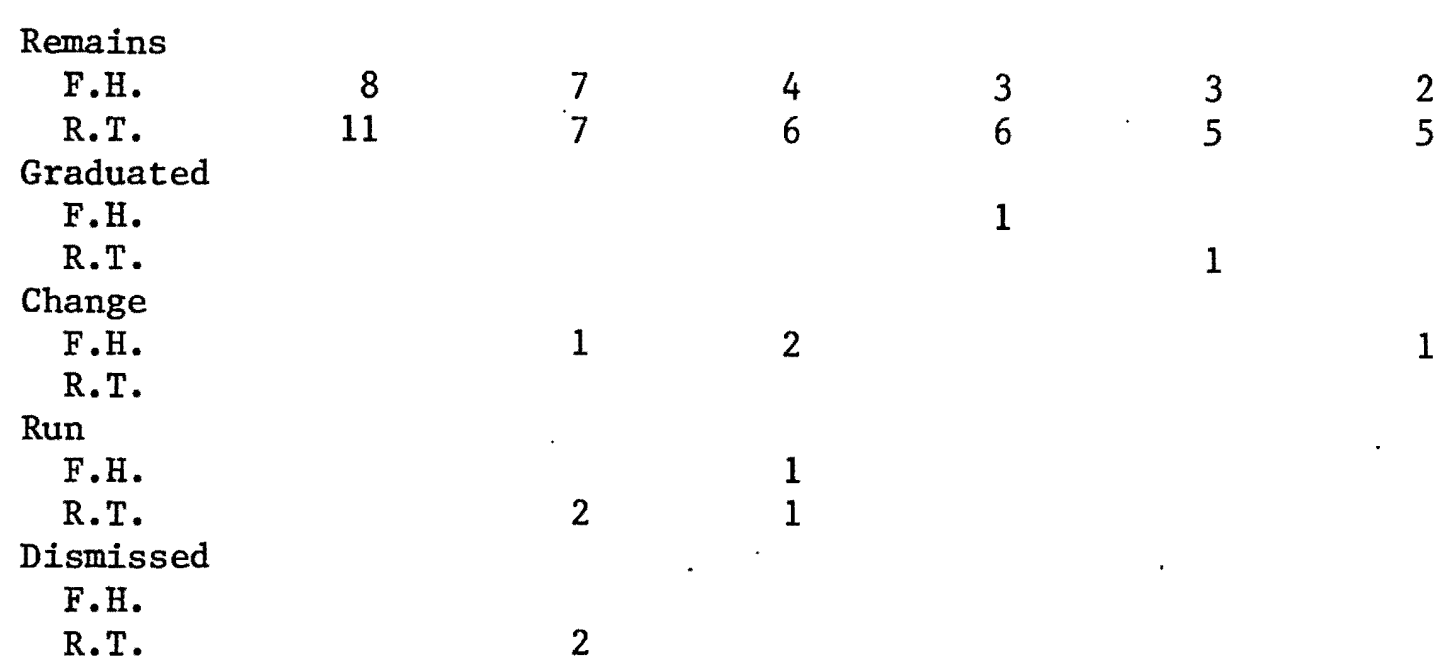

Four of the eleven in the R.T. group either ran from or were dismissed by the facility during the second month of placement. We wonder if this large early drop indicates wrong placements for these adolescents. Among the study population, the major exodus from original placements seems to have occurred by the fourth month. From that point to the end of the six-month period, only three adolescents' situations were changed; two of these completed the original plan and the third was moved to a different foster home, due to the closure of the original placement, a circumstance definitely unforeseeable at the time of placement.

\section{SUMMARY OF FINDINGS}

To summarize what the data has shown about the study population, the number of placements, according to age, peak at 15 years of age with more girls being placed in foster homes and more boys being placed in 
residential treatment. Although the number of total court referrals did not vary significantly between the placement groups, the residential treatment group had a much higher rate of involvement in burglarles. When the total number of court referrals were compared by distinguishing the underlying major problem area influencing the child's behavior, those whose behavior was considered to be "pure delinquency" had been referred to the Court far more often than those whose behaviors were associated with family dysfunction or personal emotional difficulties.

Those in the R.T. group had much less adequate relationships with peers; this difference between placement groups is not present when viewing the quality of relationships with siblings. We did not find differences in marital relationship or parent-child relationship variables between the two placement groups. We did find that strengths of the adolescents who were eventually placed in foster homes were noted and recorded more often than were strengths of adolescents going to residential treatment. Child needs in placement for structure, supervision and planned activities were reported to be present more often in those who were placed in residential treatment.

Due to inadequate data on marital statuses and the frequency with which marital partners were changed, we were not able to comment accurately on family structure. However, we did note that four of the nineteen adolescents had been adopted, a phenomenon that of ten has ramifications during adolescence when the child is developing a sense of identity.

By comparing each child's situation six months after his placement date with the original plan, we found that nine out of nineteen were 
either still following the plan or had completed it. The remaining ten had either run away from placement, had been terminated by the facillty or had been moved to a different placement by the ongoing C.S.D. worker. The largest drops in residential treatment placements occurred during the second month of placement and in foster home placements during the third month. At the end of six months, two out of eight remained in foster homes and five out of eleven remained in residential treatment, indicating that the attrition rates for foster homes are higher than for residential treatment placements. 
CHAPTER IV

CONCLUSIONS

\section{CRITIQUE OF THE STUDY}

Many important variables that might significantly influence placement decisions, plans and outcomes have not been considered in this study. Due to time and manpower limitations, examinations and evaluations were not made of placement homes and facilities, ongoing casework services provided to the child in placement or the child's adjustment to placement. It is apparent that the treatment program, the child's reaction to it, the family's involvement with treatment and coordination and communication between the social agencies involved with a child and his family are influential factors in placement outcome.

Because this study was based solely on assessment by case record, much subjective and objective information that might have influenced placement decision-making was unavailable to the researcher. Additional data, obtained through oral interviews or written questionnaires, with the adolescents, their families and placement staff might have allowed for a clearer discrimination between those who entered foster homes and those who entered residential treatment.

There are many limitations with a descriptive study by case record. The researcher has no way of knowing if unrecorded information is due to the selectivity of the worker, its non-applicability in the particular case or the unavailability of the information to the recorder. 
The written description of an individual or family may reflect, in an unacknowledged way, the client's response to the agency or the caseworker's personal reaction to the client. It is impossible to record family and child characteristics without having a frame of reference, and this perspective will influence what a worker sees in a client. By examining only cases that had been officially placed by the same C.S.D. caseworker, the present study has allowed for a personal frame of reference by acknowledging that there is a single perspective involved in describing all of the adolescents and that this perspective is consistent. As this worker had written a narrative following a similar format for each child after placement, these records reflected the style of writing, weighing of variables, importance of specific content and potential biases of one single person. Although she had had contact with all of the adolescents prior to placement, she did not - meet all of the involved families. Therefore, we must assume that at least some of the information she recorded was given to her through secondary sources, such as the court counselor, the child's observation of and attitude towards his family.

Referral letters were submitted from different Juvenile Court counselors. All of these records followed the same outline (see Appendix) and contained extensive information on the child and on his family. Due to the fact that there were several counselor-writers involved in these nineteen cases, there were differences in the types and amounts of data furnished to C.S.D. The disparity and selectivity of this information may have influenced the manner in which placement decisions were made by the C.S.D. worker, but we have no way of allowing 
for these discrepancies in this study.

The use of a checklist containing characteristics to be examined has some advantages and many disadvantages. The checklist, used in the present study, contained many variables, some of which had been noted in the cases examined prior to data collection and others which frequently are mentioned in the literature and deemed significant by clinicians. This checklist allowed the researcher to have a consistent frame of reference while examining the cases over a two-month period. It seemed sufficiently extensive to cover the major characteristics of the child and of the family. It was a clear-cut method of recording data on many different yariables.

As to the inadequacies of a checklist, it does not allow for the recording of degrees, intensities, frequencies and scope of factors. When mere mention was made of a characteristic, it was recorded as being present. When information on a characteristic was unavailable, it was recorded as being absent, which, in some cases, may have been an erroneous judgment. In addition, the significance of a particular variable may greatly differ between two families, and, thus, may be quite influential in terms of one child's behavior and may be meaningless in relation to another child's behavior.

\section{IMPLICATIONS}

Stone (1969) has written that there is a need for longitudinal studies of children during and after placement because foster care workers do not know why they fail or why they succeed and, frequently, do not even know whether they fail or succeed. The present study has 
examined many of the factors upon which placement decisions are based and has briefly presented the outcomes of these decisions in the hope of filling some of the gaps in knowledge of what is being accomplished by the current foster care system.

If we assume, as has Kraus (1971), that the ultimate criterion of "success" in placements is the survival of a placement for the length of time needed to provide substitute parental care for a child, then our study indicates that less than half of placements for adolescents, referred through the Juvenile Court System, are "successful." The reluctance in making the statement that more than half of the adolescents were "unsuccessful" in placement arises from the consideration that if a child does poorly in a particular placement, we have no way of knowing that he would or would not have done poorly with any other type of plan provided for him.

The attrition rate of our study population was high; five out of eleven in residential care and five out of eight in foster care did not "complete" the original placement plans. These figures would lead us to conclude that foster home placements for adolescents are less stable than are residential treatment placements. These findings are consistent with current practices of advocating group home placements for adolescents in need of care and supervision (Glickman, 1957; Maas and Engler, 1959; Fredericksen and Mulligan, 1972; Kline and Overstreet, 1972).

In comparing child characteristics, we found that those entering residential treatment were primarily male, with high rates of burglary, with only marginally acceptable or tolerable behavior in detention or 
shelter care and with behavior that represented anti-social acting-out. They, less adequately, performed in and related to school, had more negative relationships with peers and were viewed as having less strengths than were those placed in foster homes. They were seen to be in need of supervision, structure and limit-setting--common aspects of residential treatment programs. We have failed to uncover any single variable that differentiates these groups but, generally, those headed for foster homes are seen to be in a much more favorable position, possessing some strengths and adaptabilities.

\section{RECOMMENDATIONS}

Much more study of the placement process, including decisionmaking, planning, implementation, treatment, follow-up and evaluation, is needed in order to determine what child benefits from what placement resource. The apparent lack of empiricism and objectivity in the approaches to placement selection must be replaced with guidelines that can result from investigating the relationship of objectively definable characteristics of children and placement facilities to the "success" of placement (Kraus, 1971).

It would be desirable to replicate this study with a larger number of cases over a longer period of time in order to provide more stability. By employing several researchers who would examine more placement decisions and outcomes, a consensus could be used to objectively define the characteristics under study. With additional manpower, a research project could examine factors concurrent with placement experiences and, by' using more sophisticated quantitative measurements, might uncover 
clusters of variables significant in placement decisions and outcomes. This study partially has been an ex post facto evaluation of the effectiveness of placement decisions by looking at outcomes six months after placement. To increase the validity of such a project in the future, one might build in control groups in order to determine what changes are occurring from placement and what changes are occurring from developmental factors. Another possibility is a long-term comparative study to explore the differences in later adjustment of adolescents placed in residential treatment facilities and those placed in foster homes. 


\section{A SELECTED BIBLIOGRAPHY}

Adler, Jack. "The Delinquent-Oriented Adolescent in Residential P1acement," Child Welfare, 48:142-47 (March, 1969).

Ambinder, Walter J. "The Extent of Successive Placements Among Boys in Foster Family Homes," Child Welfare, 44:397-98 (July, 1965).

American Humane Association. Child Protective Services in the United States. Denver: American Humane Association, 1956.

Briar, Scott. "Clinical Judgment in Foster Care Placement," Child Welfare, 42:161-69 (April, 1963).

Burnes, Alan J., and Raczkowski, Leon J. "Interactive Program Applications in a Residential Center for Juvenile offendérs: A Position Paper," Child Care Quarterly, 1:272-81 (Summer, 1972).

Carey, William, et al. The Complaint Process in Protective Services for Children. Salem: Governor's Commission on Youth, 1971.

Carpenter, Kenneth S. "Halfway Houses for Delinquent Youth," Children, 10:224-29 (Nov.-Dec., 1963).

Charnley, Jean. The Art of Child Placement. Minneapolis: University of Minnesota Press, 1955.

Eisner, Victor. The Delinquency Label: The Epidemiology of Juvenile Delinquency. New York: Random House, 1969.

Fanshel, David. "The Exit of Children from Foster Care: An Interim Research Report," Child Welfare, 50:65-81 (Feb., 1971).

Feldman, Ronald A., et al. "Treating Delinquents in Traditional Agencies," Social Work, 17:72-78 (Sept., 1972).

Foy,. Edward. "The Decision-Making Problem in Foster Care," Child Welfare, 46:498-503. (Nov., 1967).

Fredericksen, Hazel, and Mulligan, R. A. The Child and His Welfare. San Francisco: W. H. Freeman and Co., 1972.

Gil, David. "Developing Routine Follow-Up Procedures for Child Welfare Services," Child Welfare, 43:229-40 (May, 1964).

Glassock, Thomas T. "Placement Prescription for Adolescents," Child Welfare, 38:10-15 (July, 1959). 
Hunter, Leslie W. "Foster Homes for Teenagers," Children, 11:234,243 (Nov.-Dec., 1964).

Hutchins, Kaye, et al. "Children Without Futures: A Feasibility Study Comparing Characteristics of Families Who Have Children Placed in Long and Short-Term Foster Care." Unpublished Master's thesis, School of Social Work, Portland State University, 1972.

Jenkins, Shirley. "Duration of Foster Care: Some Relevant Antecedent Variables," Child Welfare, 46:450-56 (Oct., 1967).

, and Sauber, Mignon. Paths to Child Placement: Family Situations Prior to Foster Care. New York: Community Council of Greater New York, 1966.

Jesness, Carl F. "Comparative Effectiveness of Two Institutional Programs for Delinquents," Child Care Quarterly, 1:119-30 (Winter, 1971-72).

Kline, Draza, and Overstreet, Helen-Mary Forbush. Foster Care of Children: Nurture and Treatment. New York: Columbia University Press, 1972.

Konopka, Gisela. "Adolescence in the 1970s," Child Welfare, 50:553-59 (Nov., 1971).

Korner, Harold. "Differential Diagnosis As It Affects the Choice of Placement for the Acting-Out Child," Child Welfare, 42:29-37 (Jan., 1963).

Kratcoski, Peter C. "Differential Treatment of Delinquent Boys and Girls in Juvenile Court," Child Welfare, 53:16-21 (Jan., 1974).

Kraus, Jonathan. "Predicting Success of Foster Placements for SchoolAge Children," Social Work, 16:63-72 (Jan., 1971).

Littner, Ner. "The Child's Need to Repeat His Past: Some Implications for Placement," Social Service Review, 34:128-48 (June, 1960).

Maas, Henry S., and Engler, Richard E., Jr. Children In Need of Parents. New York: Columbia University Press, 1959.

Martin, John M. "Case Studies of Delinquents: Incorporating the Sociological Approach," Social Work, 4:16-21 (Oct., 1959).

Matek, Ord. "Differential Diagnosis for Differential Placement of Children," Child Welfare, 43:340-48 (July, 1964).

Meisels, Joseph F., and Loeb, Martin B. "Unanswered Questions About Foster Care," Social Service Review, 30:239-46 (Sept., 1956). 
Phillips, Michael H., et al. Factors Associated with Placement Decisions in Child Welfare. Research Center: Child Welfare League of America, Inc., 1971.

Sauber, Mignon. "Preplacement Situations of Families: Data For Planning Services," Child Welfare, 46:443-49 (Oct., 1967).

Schorr, Alvin L. (ed.). Children and Decent People. New York: Basic Books, Inc., 1974.

Shanley, Fred J. "Middle-Class Delinquency As a Social Problem," Faces of Delinquency, ed. John P. Reed and Fuad Baali, 260-70. New Jersey: Prentice-Ha11, Inc., 1972.

Stone, Helen D. Reflections on Foster Care. New York: Child Welfare League of America, Inc., 1969.

(ed.). Foster Care in Question: A National Reassessment by Twenty-One Experts. New York: Child Welfare League of America, Inc., 1970.

Taylor, Delores A., and Starr, Philip. "Foster Parenting: An Integrative Review of the Literature," Child Welfare, 46:371-85 (July, 1967).

Whittaker, James K. "Group Care for Children: Guidelines for Planning," Social Work, 17:51-61 (Jan., 1972).

Wolins, Martin, and Piliavin, Irving. Institution or Foster Family: A Century of Debate. New York: Child Welfare League of America, Inc., 1964.

Young, Leontine. Wednesday's Children: A Study of Child Neglect and Abuse. New York: McGraw-Hi11 Co., 1964. 


\section{APPENDIX}

\section{OUTLINE FOR REFERRAL TO FOSTER CARE}

1. IDENTIFYING INFORMATION: Names, ages, addresses of all members of the immediate family; length of residence in Oregon; type and length of employment; mother's maiden name; date and place of child's birth; physical description of the child including outstanding features.

2. DESCRIPTION OF PROBLEM:- In cases of a child with delinquency history, describe the behavior exhibited, the duration of the problem, and circumstances leading up to it. In the case of a more dependent type of child, a descriptive statement of life events creating adverse dependent circumstances is needed.

3. SCHOOL - PERFORMANCE, ATTITUDE, APTITUDE: The grade level achieved, and whether child has been in special education classes. We need to know scholastic aptitudes, including strengths and weaknesses in specific areas. Attitudes about school attendance.

4. PSYCHIATRIC and/or PSYCHOLOGICAL INFORMATION: Please send us copies of any psychiatric or psychological evaluation available.

5. FAMILY RELATIONSHIPS: Include information concerning the basic stability of the family and patterns of total family functioning; child-parents and parent-child attitudes; sibling relationships; other relatives concerned or interested. Include information regarding divorces, deaths, etc.

6. RELIGION: Of child, mother and father.

7. PHYSICAL AND DENTAL HEALTH: Describe state of dental and medical health. Include any medical history available.

8. PEER ASSOCIATION: Describe kind of groups the child associates with or identifies with.

9. LENGTH OF TIME SPENT WORKING WITH THE CHILD AND HIS FAMILY: What help has been provided or what effort has been made to maintain the child in his own home?

10. REASON FOR REFERRAL TO FOSTER CARE: Describe the dynamics of the situation which indicate that foster care is the treatment of choice: Are both the child and parents accepting of foster care? Has placement with relatives been ruled out? 
11. PARENTS' AND CHILD'S ATTITUDES ABOUT PLACEMENT: May we expect the child and parents to be supportive and cooperative? Will the parents be able to participate in treatment?

12. LEGAL STATUS: Is the child a Court Ward? If not, what is legal status?

13. FINANCIAL: Are the parents aware they will be expected to make payment for foster care? How do they feel about this? 